University of South Carolina

Scholar Commons

1992

\title{
Hydrogen Diffusion, Solubility, and Water Uptake in Dow's Short- Side-Chain Perfluorocarbon Membranes
}

Yu-Min Tsou

M. C. Kimble

Texas A \& M University - College Station

Ralph E. White

University of South Carolina - Columbia, white@cec.sc.edu

Follow this and additional works at: https://scholarcommons.sc.edu/eche_facpub

Part of the Chemical Engineering Commons

\section{Publication Info}

Journal of the Electrochemical Society, 1992, pages 1913-1917.

(c) The Electrochemical Society, Inc. 1992. All rights reserved. Except as provided under U.S. copyright law, this work may not be reproduced, resold, distributed, or modified without the express permission of The Electrochemical Society (ECS). The archival version of this work was published in Journal of the Electrochemical Society.

http://www.electrochem.org/

DOI: $10.1149 / 1.2069521$

http://dx.doi.org/10.1149/1.2069521

This Article is brought to you by the Chemical Engineering, Department of at Scholar Commons. It has been accepted for inclusion in Faculty Publications by an authorized administrator of Scholar Commons. For more information, please contact digres@mailbox.sc.edu. 
R. K. Willardson and A. C. Beer, Editors, Vol. 3, Chap. 6, Academic Press, New York (1967).

14. A. Di Paola, F. Di Quarto, and C. Sunseri, Corros. Sci., 26, 935 (1986).

15. W. Gärtner, Phys. Rev., 116, 84 (1959).

16. R. Kupferschmid, Diploma work, ETH-Zürich (1990).

17. A. Di Paola, D. Shukla, and U. Stimming, Electrochim. Acta, 36, 345 (1991).

18. P. Schmuki and H. Böhni, To be published.

19. V. Halpern, Philos. Mag. B, 49, L57 (1984).

20. W. Schottky, Z. Phys., 113, 367 (1939).

21. W. Schottky, ibid., 118, 539 (1942).

22. U. Stimming and J. W. Schultze, Ber. Bunsenges. Phys. Chem., 80, 1297 (1976).

23. N. Wisdom and N. Hackerman, This Journal, 109, 1067 (1962).

24. R. V. Moshtev, Ber. Bunsenges. Phys. Chem., 72, 452 (1968).
25. J. Orenstein and M. A. Kastner, Phys. Rev. Lett., 49, 1421 (1981).

26. T. Tiede and A. Rose, Solid State Commun., 37, 49 (1981).

27. A. Newmark and U. Stimming, J. Electroanal. Chem., 204, 197 (1986).

28. D. J. Dunstan, J. Phys. C., 16, L567 (1983).

29. H.-R. Sprünken, R. Schuhmacher, and R. N. Schindler, Ber. Bunsenges. Phys. Chem., 84, 1040 (1980).

30. G. Popkirov and R. N. Schindler, Solar Energy Mater., 13, 161 (1986).

31. D. Gorse, B. Rondot, and M. Da Cunha Belo, Corros. Sci., 30, 23 (1990).

32. C. Sunseri, S. Piazza, A. Di Paola, and F. Di Quarto, This Journal, 134, 2410 (1987).

33. A. M. P. Simoes, M. G. S. Ferreira, B. Rondot, and M. da Cunha Belo, ibid., 137, 82 (1990).

\title{
Hydrogen Diffusion, Solubility, and Water Uptake in Dow's Short-Side-Chain Perfluorocarbon Membranes
}

\author{
Yu-Min Tsou* \\ Dow Chemical USA, Texas Applied Science and Technology Laboralories, Freeport, Texas 77541 \\ M. C. Kimble, ${ }^{*, 1}$ and R. E. White* \\ Department of Chemical Engineering, Texas A\&M University, College Station, Texas 77843-3122
}

\begin{abstract}
Hydrogen gas diffusion coefficients and solubilities as well as water uptake values are reported for Dow's short-sidechain perfluoro-sulfonic and -carboxylic membranes of different equivalent weight ( $E W$ ). The diffusion coefficients and solubilities were determined with an electrochemical test cell. Hydrogen solubility decreases with increasing EW in the lower EW range and tends to level off at higher EWs for both types of membranes. Both hydrogen solubility and diffusion coefficients of a sulfonic membrane with EW higher than 800 are higher than the corresponding values of a carboxylic membrane of similar EW. An unusual maximum is observed in the diffusion coefficient-EW plot of sulfonic membranes. Water uptake decreases with increasing $\mathrm{EW}$ for both types of membranes. Various trends in the hydrogen diffusion coefficients and solubilities are discussed in terms of a number of physical and morphological properties, such as the percent of crystallinity, intrusion of one phase into another phase, extent of ion-pair formation, and pore sizes of membranes.
\end{abstract}

In most applications involving perfluorinated cation exchange membranes such as chlor-alkali cells, water electrolysis, fuel cells, and electro-organic synthesis, gas permeation through the membrane causes a decrease in the current efficiency of the cell. A fundamental understanding of this gas diffusion process in these membranes may lead to a method of minimizing the resulting efficiency loss. Also, this understanding may provide valuable information about the effect of various parameters such as structure, morphology, and water content on the gas permeation rate through ion exchange membranes. In the present work, hydrogen permeation rates through Dow's short-side-chain perfluorocarbon sulfonic and carboxylic acid ion exchange polymers are reported. The structures of these membranes are shown in Fig. 1 together with the structure of Du Pont's Nafion ${ }^{\text {* }}$ ion exchange membrane.

The short-side-chain polymers in the Dow membranes would be expected to cause significantly different permeation rates and other properties relative to those of Nafion. For example, Ogumi et al. (1) studied the permeation of hydrogen through Nafion and obtained values for the solubility and diffusion coefficient of hydrogen in Nafion which are different from those reported here for Dow membranes. Also, Tant et al. (2) discussed the effect of functional chain length on the dynamic mechanical properties and crystallinity differences of the Dow and Du Pont membranes. In this work, the hydrogen permeation rates and water uptake in Dow's short-side-chain sulfonic and

* Electrochemical Society Active Member.

1 Present address: Advanced Engineering Technology, Los Alamos National Laboratory, Los Alamos, NM 87545 carboxylic acid membranes were studied over a wide range of equivalent weights.

\section{Experimental}

Materials.-The membranes used in the experiments were prepared by first coating a thin layer of a mixture of platinum black and perfluorocarbon binder suspended in

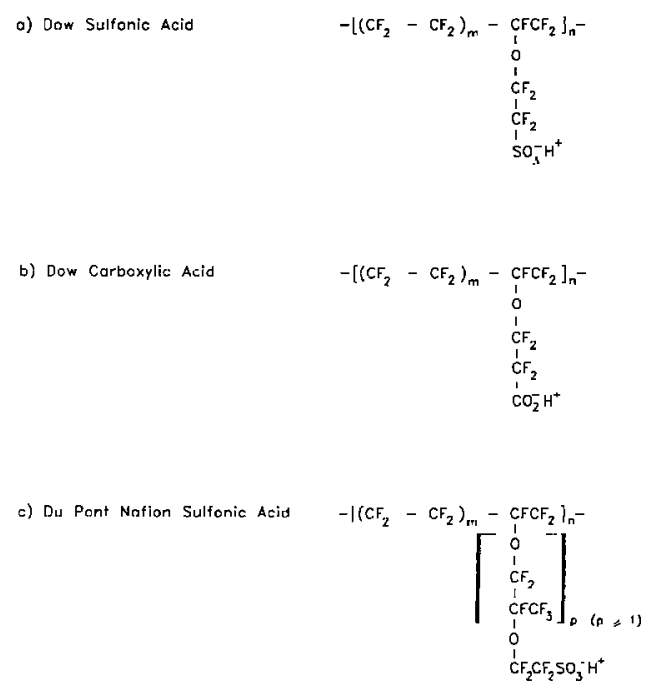

Fig. 1. Struchure of perfluorocarbon ion exchange polymers. 


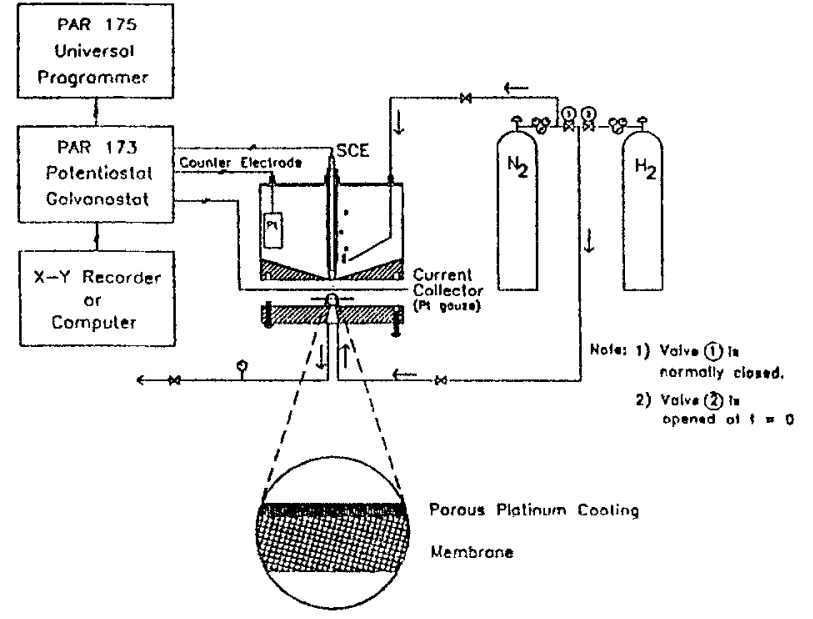

Fig. 2. Schematic representation of the experimental apparatus of the electrochemical monitoring technique.

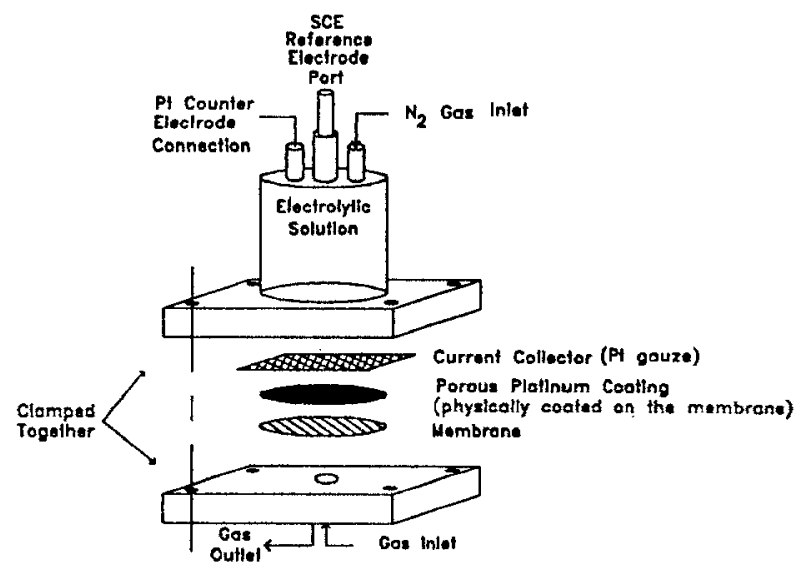
cell.

Fig. 3. Detailed schematic representation of the electrochemical test

Freon 113 onto one side of the membrane. The coating procedure consisted of applying a sequence of pressure and heat to bind the platinum black onto the surface of the membrane. Next, the coated membranes were soaked in a $25 \%$ sodium hydroxide solution for $6 \mathrm{~h}$ at $70^{\circ} \mathrm{C}$ followed by equilibrating the membrane in a $0.5 \mathrm{M} \mathrm{Na} \mathrm{Na}_{2} \mathrm{SO}_{4}$ solution at room temperature. The thickness of the membrane layer (excluding the platinum black layer) was determined after the experiments were performed by measuring a magnified cross section of each membrane.

Procedures.-A schematic representation of the experimental apparatus used for the electrochemical monitoring is shown in Fig. 2 and 3 . All electrochemical measurements were performed with a Model 175 universal programmer and Model 173 potential/galvanostat [Princeton Applied Research (PAR), Princeton, NJ] at room temperature. The reference electrode was a saturated calomel electrode and the counterelectrode was a platinum wire. The electrolyte used was a $0.5 M \mathrm{Na}_{2} \mathrm{SO}_{4}$ solution. The monitoring technique consists of measuring the current generated as all hydrogen gas that passes through the membrane is oxidized under mass-transfer limiting conditions. The resulting data can then be analyzed by a technique described by Kimble et al. (3) to determine the hydrogen gas diffusion coefficient and solubility in the membrane. The water uptake of the membranes was determined by following a procedure similar to that given by Yeager et al. (4). This procedure includes correcting for any electrolyte uptake that also occurs during the uptake of water.

\section{Results and Discussion}

Water content.-The water content of ion exchange membranes is known to affect their transport properties and was, consequently, determined as a part of this work.
Table I. Water uptake of various Dow membranes equilibrated with $0.5 \mathrm{M} \mathrm{Na}_{2} \mathrm{SO}_{4}$.

\begin{tabular}{lrcc}
\hline $\begin{array}{c}\text { Membrane } \\
\text { type }\end{array}$ & $E W$ & $\frac{\mathrm{g} \mathrm{H}_{2} \mathrm{O} \text { uptake }}{\mathrm{g} \mathrm{dry} \text { polymer }}$ & $\begin{array}{c}\text { Volume } \\
\text { fraction of } \\
\text { water, } f_{\mathrm{w}}^{\mathrm{a}}\end{array}$ \\
\hline Sulfonic & 839 & 0.194 & 0.29 \\
Sulfonic & 935 & 0.157 & 0.25 \\
Sulfonic & 1031 & 0.152 & 0.24 \\
Sulfonic & 1147 & 0.118 & 0.20 \\
Carboxylic & 721 & 0.226 & 0.32 \\
Carboxylic & 847 & 0.184 & 0.28 \\
Carboxylic & 908 & 0.143 & 0.23 \\
Carboxylic & 1011 & 0.098 & 0.17
\end{tabular}

${ }^{a} f_{\mathrm{w}}=\mathrm{g} \mathrm{H}_{2} \mathrm{O} / 1 \mathrm{~g} / \mathrm{cm}^{3} /\left(\mathrm{g} \mathrm{H}_{2} \mathrm{O} / 1 \mathrm{~g} / \mathrm{cm}^{3}+\mathrm{g}\right.$ polymer $\left./ 2.1 \mathrm{~g} / \mathrm{cm}^{3}\right)$, where it has been assumed that the density of water is $1 \mathrm{~g} / \mathrm{cm}^{3}$ and that the density of the fluorocarbon is $2.1 \mathrm{~g}^{-\mathrm{cm}^{3}}, 7,12$

The method used to determine the water content consisted of the following steps. First, a membrane sample was saturated with electrolyte $\left(0.5 \mathrm{M} \mathrm{Na}_{2} \mathrm{SO}_{4}\right)$ and its mass was determined by weighing the sample $\left(M_{\mathrm{T}}\right)$. This membrane sample was then boiled in water for several hours to drive out the electrolyte. The resulting wash solution from this step was analyzed by inductively coupled plasma optical emission spectroscopy to determine the mass of the electrolyte, $\mathrm{Na}_{2} \mathrm{SO}_{4},\left(M_{\mathrm{E}}\right)$ that was absorbed during the saturation step. Next, the membrane sample was heated in a vacuum at $120^{\circ} \mathrm{C}$ for one or two days, removed and weighed to determine the mass of the membrane $\left(M_{M}\right)$. Finally, the mass of water $\left(M_{\mathrm{W}}\right)$ was determined by subtracting the mass of the membrane and the mass of the electrolyte from the total mass: $M_{\mathrm{W}}=M_{\mathrm{T}}-M_{\mathrm{M}}-M_{\mathrm{E}}$. The amount of absorbed $\mathrm{Na}_{2} \mathrm{SO}_{4}$ was very small. For the membranes used in this work, $\mathrm{Na}_{2} \mathrm{SO}_{4} \mathrm{~g} / \mathrm{g}$ polymer was in the range of $0.1 \%-0.7 \%$; the mole ratio of $\mathrm{Na}_{2} \mathrm{SO}_{4}$ absorbed $\mathrm{H}_{2} \mathrm{O}$ was in the range of $0.17 \%-0.41 \%$. The results of these measurements, $M_{\mathrm{W}} / M_{\mathrm{M}}$, are presented as grams of $\mathrm{H}_{2} \mathrm{O}$ uptake/ grams dry polymer in Table I and Fig. 4. The trend is similar to that of Nafion membranes of different equivalent weights $(5,6)$. However, one should be careful in comparing absolute values of water content of membranes because different electrolytes may give different water content values.

Solubilities and diffusion coefficients.-The solubilities of hydrogen gas in the membranes studied here are presented in Table II and Fig. 5 as a function of equivalent weight (EW). As shown in Fig. 5, the solubility is higher for a sulfonic membrane than for a carboxylic membrane of comparable EW. Interestingly, for both types of mem-

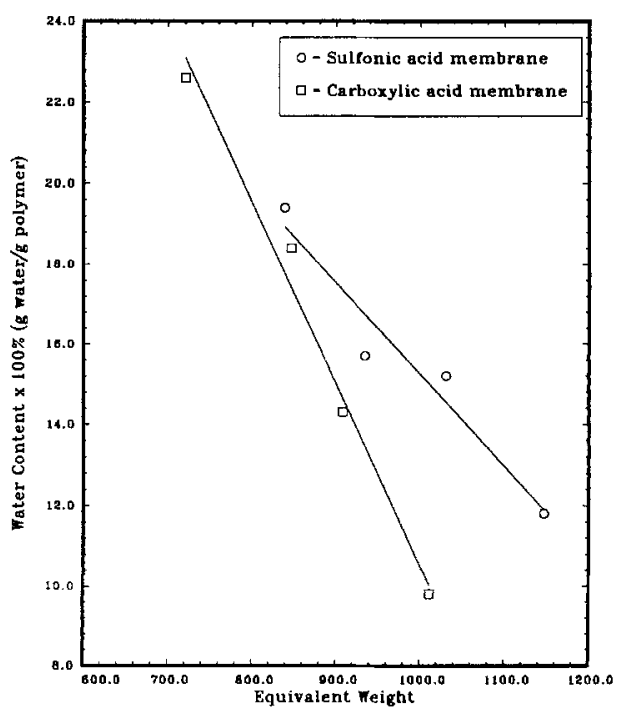

Fig. 4. Water contents of Dow perfluorocarbon membranes (equilibrated with $0.5 \mathrm{M}$ sodium sulfate). 
Table II. Solubilities and adjusted solubilities of hydrogen in various Dow membranes equilibrated with $0.5 \mathrm{M} \mathrm{Na}_{2} \mathrm{SO}_{4}$.

\begin{tabular}{|c|c|c|c|c|c|c|}
\hline Material & $\mathrm{EW}$ & $\begin{array}{c}\text { Thickness } \\
\text { (mils) }\end{array}$ & $\begin{array}{c}\mathrm{C}^{\circ} \\
(\mathrm{m} M)\end{array}$ & $\begin{array}{l}C^{\circ} / f^{a} \\
(\mathrm{~m} M)\end{array}$ & $\begin{array}{l}C^{\circ} / f_{\mathrm{g}}^{\mathrm{b}} \\
(\mathrm{mM})\end{array}$ & $\begin{array}{c}C^{\circ} /\left(f_{\mathrm{w}}\right)^{0.5} \\
(\mathrm{mM})\end{array}$ \\
\hline Dow sulfonic & 771 & 5.14 & $2.97 \pm 0.155$ & - & - & - \\
\hline Dow sulfonic & 839 & 9.81 & $1.85 \pm 0.0525$ & 6.38 & 2.61 & 3.44 \\
\hline Dow sulfonic & 935 & 5.05 & $0.784 \pm 0.0132$ & 3.14 & 1.05 & 1.57 \\
\hline Dow sulfonic & 1031 & 5.43 & $0.807 \pm 0.0583$ & 3.36 & 1.06 & 1.65 \\
\hline Dow sulfonic & 1147 & 6.10 & $0.797 \pm 0.0212$ & 3.99 & 1.00 & 1.78 \\
\hline Dow carboxylic & 721 & 6.31 & $1.36 \pm 0.0578$ & 4.25 & 2.00 & 2.40 \\
\hline Dow carboxylic & 908 & 5.69 & $0.421 \pm 0.0230$ & 1.83 & 0.55 & 0.88 \\
\hline Dow carboxylic & 1011 & 6.73 & $0.431 \pm 0.00673$ & 2.54 & 0.52 & 1.05 \\
\hline
\end{tabular}

\footnotetext{
${ }^{\mathrm{a}} f_{\mathrm{w}}$ is the volume fraction of water in the membrane as given in Table I.
}

${ }^{\mathrm{b}} f_{\mathrm{b}}$ is the volume fraction of fluorocarbon in the membrane: $f_{\mathrm{p}}=1-f_{\mathrm{w}}$

Table III. Diffusion coefficients of hydrogen in various Dow membranes equilibrated with $0.5 \mathrm{M} \mathrm{Na}_{2} \mathrm{SO}_{4}$.

\begin{tabular}{lrc}
\hline $\begin{array}{c}\text { Membrane } \\
\text { type }\end{array}$ & $E W$ & $D \times 10^{6}\left(\mathrm{~cm}^{2} / \mathrm{s}\right)$ \\
\hline Sulfonic & 771 & $1.58 \pm 0.05$ \\
Sulfonic & 839 & $1.94 \pm 0.03$ \\
Sulfonic & 935 & $2.15 \pm 0.02$ \\
Sulfonic & 1031 & $1.84 \pm 0.08$ \\
Sulfonic & 1147 & $0.94 \pm 0.02$ \\
Carboxylic & 721 & $1.71 \pm 0.04$ \\
Carboxylic & 847 & $1.25 \pm 0.05$ \\
Carboxylic & 908 & $0.47 \pm 0.004$ \\
Carboxylic & 1011 &
\end{tabular}

branes the solubility shows a transition around $900 \mathrm{EW}$. For membranes with EW higher than 900 , the solubility varies very little with the $\mathrm{EW}$. However, for membranes with $\mathrm{EW}$ lower than 900 the solubility tends to increase rapidly as the EW is decreased. Note that below $900 \mathrm{EW}$, the hydrogen gas solubilities in the membranes are much lower than the solubility of hydrogen $(31.3 \mathrm{mM})$ in Teflon (7); but they are significantly higher than the solubility of hydrogen $(0.78 \mathrm{mM})$ in water (8), especially for sulfonic membranes.

Table III and Fig. 6 present the diffusion coefficients of hydrogen through sulfonic and carboxylic membranes as a function of $\mathrm{EW}$. As shown in Fig. 6, the diffusion coefficient for hydrogen shows a maximum at about $950 \mathrm{EW}$ for the sulfonic membranes. On the other hand, at around that $\mathrm{EW}$ there is a significant change in the slope for carboxylic membranes.

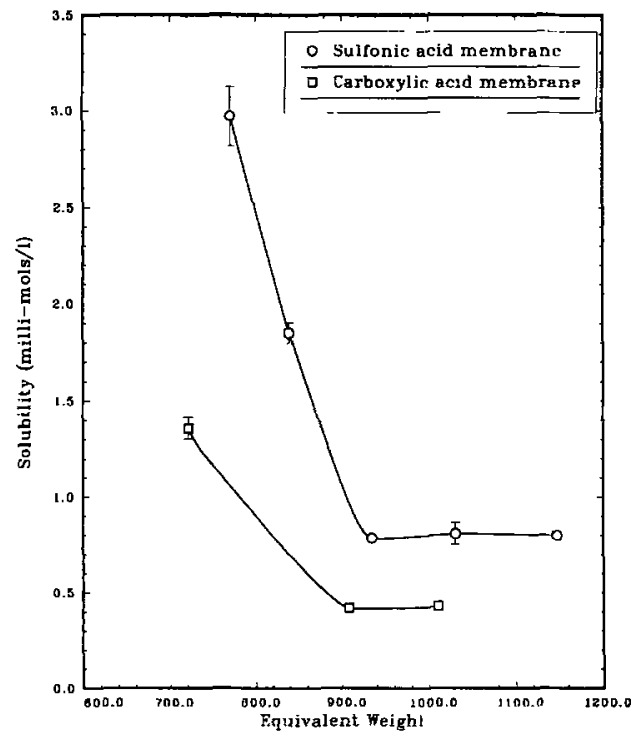

Fig. 5. Hydrogen solubility in membranes of various equivalent weight.
It has been known for a long time that there is pronounced phase separation in fluorocarbon membranes (5). Ionic groups aggregate together to form ionic clusters which are also the regions where most water molecules reside. The following discussions are based on this type of morphology. The results shown in Table II indicate that the hydrogen diffusion path is probably not entirely in the aqueous phase of a membrane. If it were, the corrected solubilities, $C^{\circ} / f_{\mathrm{W}}$, where $f_{\mathrm{W}}$ is the volume fraction of water in the membrane (see Table II), would be close to the solubility of hydrogen in water. But the data in Table II do not support this hypothesis. The hydrogen diffusion path cannot be entirely in the fluorocarbon region either because the corrected solubilities for the fluorocarbon region, $C^{\circ} / f_{\mathrm{p}}$, are much smaller than the solubility of hydrogen in Teflon. Since the solubility of hydrogen in these Dow membranes is significantly different from either that in water or that in Teflon, it is very likely that hydrogen molecules diffuse through the interfacial areas between the aqueous phase and the fluorocarbon phase. This seems very reasonable considering the very different solubilities and diffusion coefficients of hydrogen in the two phases. The greater solubility of the hydrogen in Teflon relative to water favors a diffusional path through the fluorocarbon phase. On the other hand, the greater diffusion coefficient for hydrogen in water relative to Tefion $\left(4.5 \times 10^{-5} \mathrm{~cm}^{2} / \mathrm{s}(9,10)\right.$ vs. $2 \times 10^{7} \mathrm{~cm}^{2} / \mathrm{s}$ ) (7) favors a diffusional path through the aqueous phase. The combined effect of these two factors could very likely lead to a diffusional path through the interfacial areas.

Previously Ogumi et al. (1) studied hydrogen and oxygen permeation through Nafion membranes with sulfonate ion exchange groups and various counterions. They concluded (1) that both gases diffuse through the "intermediate region," which they defined as the flexible amor-

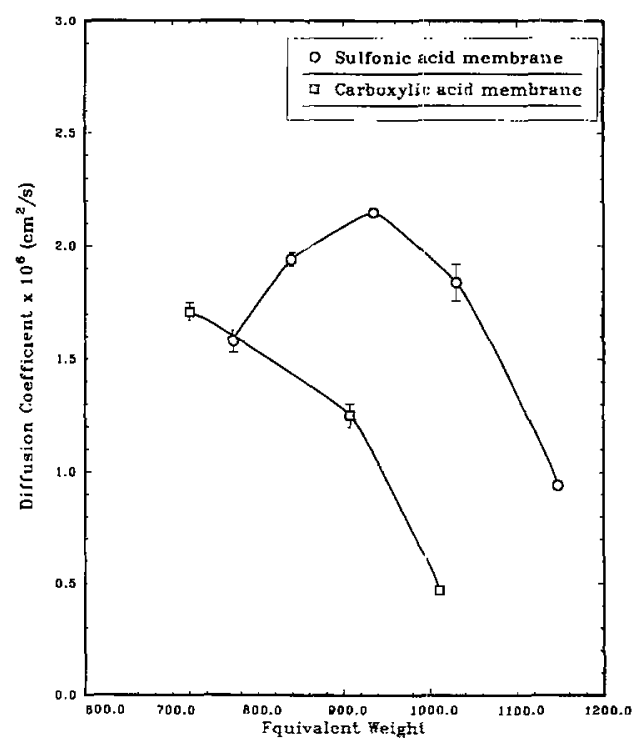

Fig. 6. Hydrogen diffusion coefficients in membranes of various equilvalent weight. 
phous part of PTFE backbone with the contribution from permeation through aqueous (ionic cluster) region to be small. As will be discussed more in the following text, we also believe that hydrogen molecules diffuse through interfacial areas. However, we think the substantial portion of the "interfacial areas" is in the aqueous phase. Our conclusion is based on the relatively larger range of observed diffusion coefficients and solubilities than the range observed by Ogumi et al. The availability of a large range of EW for both sulfonic and carboxylic membranes in the present work provided the opportunity to look through a bigger window.

Several factors need to be considered when trying to understand the trends in the values of the solubilities and diffusion coefficients as a function of $\mathrm{EW}$. These are: (i) the available interfacial region which is related to the water content; ( $i i)$ the intrusion of the fluorocarbon phase into the aqueous phase, (iii) the percent of crystallinity since the crystalline region is believed to be impermeable to hydrogen and it is expected to decrease the extent of intrusion of the amorphous fluorocarbon region into the aqueous phase; and ( $i v$ ) the ionic groups in the interfacial areas.

For membranes with EWs higher than 900 the solubilities are much closer to that in water than that in Teflon (Table II). This fact suggests that the hydrogen diffusional path of these membranes does not include the fluorocarbon phase, presumably the diffusion is confined to the aqueous phase in the interfacial area. However, the significantly higher corrected solubilities, $\mathrm{C}^{\circ} / \int_{\mathrm{W}}$, for hydrogen in membranes relative to that in water suggest that the interaction of hydrogen gas molecules with the fluorocarbon moieties is significant. This interaction could well be the reason for the observed higher solubility. Hydrophobic interaction has been found to affect the affinity of charged bulky ions, such as Ru(bipyridine) ${ }_{3}^{21}$, residing in the interfacial area of Nafion membranes $(11,12)$. The strength of the hydrophobic interaction is expected to increase with the extent of intrusion of fluorocarbon into the aqueous phase. By this rationalization one would expect that the more the fluorocarbon intrudes into the aqueous phase, the higher the apparent hydrogen solubility. Also, it is plausible to expect that a decrease in the percent of crystallinity would favor a higher extent of intrusion of fluorocarbon phase into the aqueous phase. This appears to be what occurs for sulfonic membranes below EW 900, where the solubility shows an increasing trend below this range (Fig. 5 and Table II). Even after correcting for the different available interfacial areas, which are assumed to be proportional to the square root of the volume fraction of the water to get the "normalized solubilities," $\left.C^{\circ} / f_{\mathrm{W}}\right)^{0.5}$ (Table II), the trend is still clear. (Assuming cylindrical channels of aqueous phases then the volume of the channels would be $\pi R^{2} d$, where $R$ is the radius and $d$ is the length of the channel. On the other hand, the surface area is $2 \pi R d l$, where $l$ is the thickness of the interfacial area. Therefore, for two different membranes the ratio of the volume fraction is proportioned to $\left(R_{1} / R_{2}\right)^{2}$ and the ratio of the interfacial area is proportioned to $R_{1} / R_{2}$. This explanation is consistent with the observations made by Tant et al. (2). They reported that measurable crystallinity starts to appear when the $\mathrm{EW}$ is increased above $800-1000$ for Dow sulfonic membrane in the sodium form. The significant decrease in crystallinity for membranes with equivalent weight lower than 800 would increase the extent of intrusion of the fluorocarbon phase into the aqueous phase and result in a higher apparent hydrogen solubility. There is no available crystallinity data for the carboxylic membranes, but it appears that a similar transition in the solubility occurs around $900 \mathrm{EW}$ for carboxylic membranes.

If the significant increase in the intrusion of the fluorocarbon phase into the aqueous phase is indeed the cause of the increase in hydrogen solubility for membranes with equivalent weight lower than 900 (i.e., around the transition region), one should be able to find the corresponding effect of phase intrusion in the EW dependence of diffusion coefficients. First, the intrusion of the fluorocarbon phase into the aqueous phase would result in more tortuous boundaries between the two phases. As discussed above, hydrogen diffusion is believed to be confined to the interfacial areas, so the tortuous boundaries would result in a tortuous path for hydrogen diffusion and, therefore, a lower apparent diffusion coefficient. It should be pointed out that this intrusion-tortuosity effect is not the only factor which would influence the diffusion coefficient. Another important factor is pore diameter, i.e., the ionic cluster size. Gierke and Hse (6) reported that water self-diffusion coefficient in Du Pont sulfonic membranes decreased with EW. They attributed this to the smaller ionic cluster sizes in membranes of higher equivalent weight. It is reasonable to assume the same trend would also be true for Dow membranes. Also, since a hydrogen molecule is smaller than a water molecule, the hydrogen diffusion rate in the aqueous phase near the interfacial area would be expected (13) to behave in a similar manner, i.e., the diffusion coefficient of hydrogen would be expected to decrease with increasing EW. The data of sulfonic membranes in Fig. 6 can be rationalized in terms of the relative importance of the ionic-cluster-size effect and the phase intrusion (tortuosity) effect. At EW higher than 950, the phase intrusion effect is negligible so that the diffusion coefficient decreases with increasing $\mathrm{EW}$. At $\mathrm{EW}$ lower than 900 , the ionic-cluster-size effect is dominated by the phase-intrusion effect, so the opposite trend is observed. Note that unlike the case for sulfonic membranes, a maximum is not present for the carboxylic membranes in Fig. 6, which indicates that the morphology for these two membranes may be different. Yeager and co-workers (14) obtained similar conclusions from infrared absorbance measurements. They found that there is much less intrusion of the fluorocarbon phase into the aqueous phase for Du Pont carboxylic membranes than for Du Pont sulfonic membranes (both with about 1100-1200 EW).

Finally, higher hydrogen diffusion coefficients for the sulfonic membranes relative to those for carboxylic membranes of comparable equivalent weight is consistent with the concept of the strength of site bonding, i.e., the extent of ion pairing of sodium ions with ion exchange groups. It is well-known that carboxylate polyelectrolytes show a higher tendency of site bonding than sulfonate polyelectrolytes (15-18). This stronger site bonding would be expected to impede the diffusion of hydrogen since hydrogen molecules would have to go around the tightly bound ion pairs in the interfacial area.

\section{Conclusions}

Hydrogen solubilities and diffusion coefficients in Dow short-side-chain perfluoro-sulfonic and -carboxylic membranes can be measured in an electrochemical test cell. The observed diffusion coefficients and solubilities are consistent with a diffusional path through interfacial areas between the aqueous phase and the fluorocarbon phase. The transitions observed in the solubility-equivalent weight (EW) plot are attributed to the onset of measurable crystallinity. The increase in solubility with decreasing EW for an EW lower than 900 is attributed to the increase in the available interfacial area and higher extent of intrusion of the fluorocarbon phase into the aqueous phase resulting from a lower extent of crystallinity for membranes with lower EWs. Diffusion coefficients show a more complicated pattern. A maximum around $950 \mathrm{EW}$ in the diffusion coefficient-EW plot of sulfonic membranes is attributed to the compensation effect of two parameters: the extent of intrusion of the fluorocarbon phase into the aqueous phase and the magnitude of the pore diameter in a membrane. The lower hydrogen diffusion coefficient for a carboxylic membrane relative to a sulfonic membrane of comparable EW is attributed to the higher extent of ionpair formation between sodium ions and carboxylic ion exchange groups than that between sodium ions and sulfonic ion exchange groups. This is true because ion-pair formation has an obstructive effect on hydrogen diffusion.

\section{Acknowledgment}

The authors are grateful for the support of this work by Dow Chemical USA. Also, the authors would like to express their gratitude to James McMichael for preparing 
samples, to Thomas J. Pisklak for cross-sectioning of the membranes, to Jim Smith and co-workers for assistance in the analysis of water uptake of the membranes, to Larry Smith and Bob Aikman for supplying the membranes, and to Charlie Martin for helpful discussions.

Manuscript submitted Dec. 23, 1991; revised manuscript received April 1, 1992.

Dow Chemical USA assisted in meeting the publication costs of this article.

\section{REFERENCES}

1. Z. Ogumi, T. Kuroe, and Z. Takehara, This Journal, 132, 2601 (1985).

2. M. R. Tant, K. P. Darst, K. D. Lee, and C. W. Martin, in "Proceedings of the ACS Division of Polymeric Materials: Science and Engineering," Vol. 60, Toronto, Ont., Canada, 1989 Spring Meeting.

3. M. C. Kimble, R. E. White, Y.M. Tsou, and R. N. Beaver, This Journal, 137, 2510 (1990).

4. H. L. Yeager, B. O'Dell, and Z. Twardowski, ibid., 129, 85 (1982).

5. T. D. Gierke, G. E. Munn, and F. C. Wilson, in "Perfluorinated Ionomer Membranes," A. Eisenberg and H. L. Yeager, Editors, ACS Symposium Series, Vol.
180, Chap. 10, Washington, DC (1982).

6. T. D. Gierke and W. Y. Hsu, ibid., Chap. 13.

7. T. Kim Gibbs and D. Pletcher, Electrochim. Acta., 25, 1105 (1980).

8. A. G. Loomis, in "International Critical Tables of Numerical Data, Physics, Chemistry, and Technology," Vol. 3, E. W. Washburn, Editor, p. 255, McGraw Hill, Inc., New York (1938).

9. A. P. Colburn and R. L. Pigford, in "Chemical Engineering Handbook," 3rd ed., J.H. Perry, Editor, p. 540, McGraw Hill, Inc., New York (1950).

10. A. H. M. Cosjin, Electrochim. Acta., 3, 24 (1962).

11. Y.-M. Tsou and F. C. Anson, This Journal, 131, 595 (1984).

12. P. C. Lee and D. Meisel, J. Am. Chem. Soc., 102, 5477 (1980).

13. T. Erdey-Gruz, "Transport Phenomena in Aqueous Solutions," Adam Hilyer, London (1974).

14. H. L. Yeager, Z. 'Twardowski, and L. M. Clarke, This Journal, 129, 324 (1982).

15. G. E. Boyd and D. P. Wilson, Macromolecules, 15, 78 (1982).

16. M. Finauda and M. Milas, ibid. , 6, 879 (1973).

17. J. Hen and U.P. Strauss, J. Phys. Chem., 78, 1013 (1974).

18. C. Tondre and R. Zana, ibid, 76, 3451 (1972).

\title{
Measurement Models for Electrochemical Impedance Spectroscopy I. Demonstration of Applicability
}

\author{
Pankaj Agarwal* and Mark E. Orazem** \\ Department of Chemical Engineering, University of Florida, Gainesville, Florida 32611
}

Luis H. Garcia-Rubio

Department of Chemical Engineering, University of South Florida, Tampa, Florida 33620

\section{ABSTRACT}

Use of measurement models is suggested as an intermediate step in the analysis of impedance data. In a manner analogous to the routine use of measurement models in the deconvolution of optical spectra, the measurement model could be used to guide development of physicoelectrochemical models by determining whether a data set is consistent with the Kramers-Kronig relations, by suggesting a form for the error structure of the data, and by providing an indication of the number and type of physical processes that can be resolved from the data. In this paper, a general measurement model is shown to apply for a wide variety of typical electrochemical impedance spectra. The application of the measurement models as a data filter will be addressed in subsequent papers.

Impedance spectroscopy has become a powerful tool for investigating the properties of electronic materials and electrochemical systems $(1,2)$. The responsc of a system to a sinusoidal perturbation can be used to calculate the impedance as a function of the frequency of the perturbation. Interpretation of electrochemical impedance spectra requires selection of an appropriate model which is regressed to the data. The most commonly used model is an electrical circuit analogue consisting of resistors, capacitors, inductors, and specialized distributed elements. Development of detailed physicoelectrochemical models is becoming more common but is still less often pursued. Selection of an appropriate model can be time consuming, particularly if a detailed physicoelectrochemical model is desired. Some of the questions that must be addressed in developing an appropriate model are:

1. Was the experimental system stationary? One distinction between electrochemical and electrical systems is that electrochemical processes are typically dynamic, i.e., the rate of electrochemical reactions can change in response to dissolution of the electrode, deposition of salt or oxide

* Electrochemical Society Student Member.

** Electrochemical Society Active Member. films, and adsorption or absorption of reacting species. If the system changed significantly during the time in which data were collected, this nonstationary behavior should be incorporated into the model.

2. How many physical processes can be resolved from the data? Electrochemical systems rarely display wellresolved peaks in the impedance spectra. Since the ultimate goal of interpreting impedance spectra is to gain insight into the physical processes that control the system, the model developed must incorporate time constants for the relevant physical processes. Another way to phrase this question is to ask whether the lack of complete agreement between the data and the model should be attributed to experimental error, to nonstationary processes, or to use of an inadequate or incomplete model.

Determination of stationary behavior.-A system can be determined to be stationary through careful experimentation, through successful regression of the data to electrical-circuit analogues, or through direct integration of the Kramers-Kronig relations. Stationary behavior can be identified experimentally by replication of the impedance spectrum. If the experimental frequency range is sufficiently broad the extrapolation of the impedance spec- 